\title{
THE CORRELATION BETWEEN THALASSEMIA WITH BODY MASS INDEX AND BLOOD GROUPS IN CHILDREN AND ADULT PATIENT IN THE PROVINCE OF BABYLON, IRAQ
}

\author{
HANANJASSIM HAMMOD ${ }^{1 *}$, THANAA ABDULMAHDI MOKIF ${ }^{1}$, HUSSEIN JASIM AL-HARBI ${ }^{2}$ \\ ${ }^{1}$ Department of Babylon Technical Institute, Al-Furat Al- Awsat Technical University, 51015 Babylon, Iraq. ${ }^{2}$ Department of College ${ }^{\text {of }}$ \\ Science, University of Babylon, Iraq. Email:dr.hanan.jh@gmail.com
}

Received: 03 May 2018, Revised and Accepted: 23 July 2018

\section{ABSTRACT}

Objective: This study aimed to evaluate the relationship between thalassemia disease and body mass index (BMI) and the correlation with blood group of thalassemia patients.

Methods: The study includes 260 persons (male+female), 200 persons were thalassemia patient (120 male and 80 female), and 60 healthy persons (30 male and 30 female) as control group; furthermore, people were divided into three group according to age 1-9, 10-19, and >20 years, and BMI and blood group were measured for all patients and healthy people.

Results: The results showed that the frequency of thalassemia in male (65\%) is higher than in female (40\%); as well as, the results showed that the age group (10-19) years is more frequent in male, while in female, the age group (1-9) years is more frequent. The results of BMI revealed a significant decrease $(\mathrm{p}<0.05)$ in all groups of thalassemia patients compared with healthy group; as well as, the results of blood group showed that the group $(\mathrm{O}+)$ is the more frequent $34 \%$ in comparison with the other blood groups.

Conclusion: We conclude that there was a strong relationship among gender, blood group (the most common blood group observed is $0+v e$ ), and BMI with thalassemia.

Keywords: Thalassemia, Body mass index, Age, Blood group.

(c) 2018 The Authors. Published by Innovare Academic Sciences Pvt Ltd. This is an open access article under the CC BY license (http://creativecommons. org/licenses/by/4. 0/) DOI: http://dx.doi.org/10.22159/ajpcr.2018.v11i9.27100

\section{INTRODUCTION}

The thalassemia is hereditary anemia caused by mutations that affect the synthesis of the globe and the protein component of the hemoglobin. Thalassemia produces massive public health problems in many parts of the world. Thalassemia is classified according to which particular globin chain produced in a reduced amount, which may lead to an imbalance in globin chain synthesis, ineffective erythropoiesis, hemolysis, and eventually to a variable degree of anemia. The main types of thalassemia are $\alpha, \beta, \delta \beta, \delta$, and $\Upsilon \beta$ [1]. There are two main types, alpha and beta thalassemia [2]. The severity of alpha and beta thalassemia depends on how many of four genes for alpha or two genes for beta globin are missing [3]. The pathophysiology of beta thalassemia is various to that of alpha thalassemia. A defect of $\alpha$-chain leads to the creation of excess chains or $\beta$-chains, which compose $\mathrm{Hb}$ Bart's and $\mathrm{Hb} \mathrm{H}$, respectively. This soluble tetramers do not precipitate in the bone marrow, and thus, erythropoiesis is more efficient than in $\beta$ thalassemia [4]. Inverse the deletion that constitutes most of the alpha thalassemia syndromes, beta thalassemia is caused by a mutation on chromosome 11 that affect all aspects of beta globin production: Transcription, translation, and the stability of the beta globin product [5].

Although there are different methods of assessing nutrition, for example, height for age, weight for age, and weight for height, but body mass index (BMI) is the most commonly used for assessing whether adults were fixed BMI values used to classify individuals, unlike child is obese, overweight, underweight, or healthy weight. Children's BMI (2-20 years of age) is classified using thresholds that take into account the child's age and sex [6], while blood group is one of the significant and relatively well-known parameters today, which exhibits a strong correlation with some common diseases such as cardiovascular diseases, gastric cancer, and HIV infection [7].

\section{METHODS}

This study was conducted on 260 persons, 200 persons were thalassemia patient ( 120 male and 80 female), and 60 healthy persons ( 30 male and 30 female) as a control group; furthermore, people were divided into three groups according to age of 1-9, 10-19, and $>20$ years. Calculate BMI by measuring the weight $(\mathrm{kg})$ and height $(\mathrm{m})$ for each person was measured BMI according to the following equation $\mathrm{BMI}=\mathrm{Wt} /(\mathrm{Ht})^{2}$ where weight $=$ weight $(\mathrm{kg})$, $(\mathrm{Ht})^{2}=$ box height $(\mathrm{m})^{2}[8]$ while the measure the blood group the materials that were used in this research is the Kit For company LORNE $[9,10]$.

Statistical analysis

The results were analyzed using the statistical system SPSS version-18 (LSD testing)

\section{RESULT}

The results showed that gender has a relationship with thalassemia. The results showed, in Fig. 1, that the rate of infection of males is higher than AAA that of females, where the percentage of males (65\%) compared to females (35\%).

As for the effect of age and its association with thalassemia, the age group (10-19 years) was the more frequent in males (43.8\%) compared to age group of 1-9 years and $>20$ years $(40.8 \%$ and $15.8 \%)$, respectively, while the category (1-9 years) was the most frequent in females (38.7\%) compared to the categories of $10-19$ years and $>20$ years $(37.5 \%$ and $23 \%$. $75 \%)$, respectively [Fig. 2].

The results indicated that the age group (10-19) was the most frequent group in males and females (40\%) compared to the age groups 1-9 and $>20$ years (38\% and $22 \%$ ), respectively, in Fig. 3. 


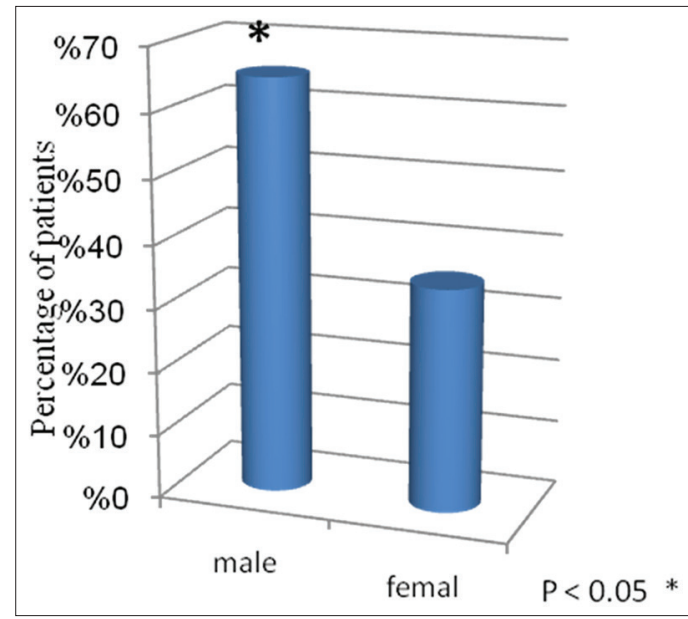

Fig. 1: Percentage of thalassemia patients by gender

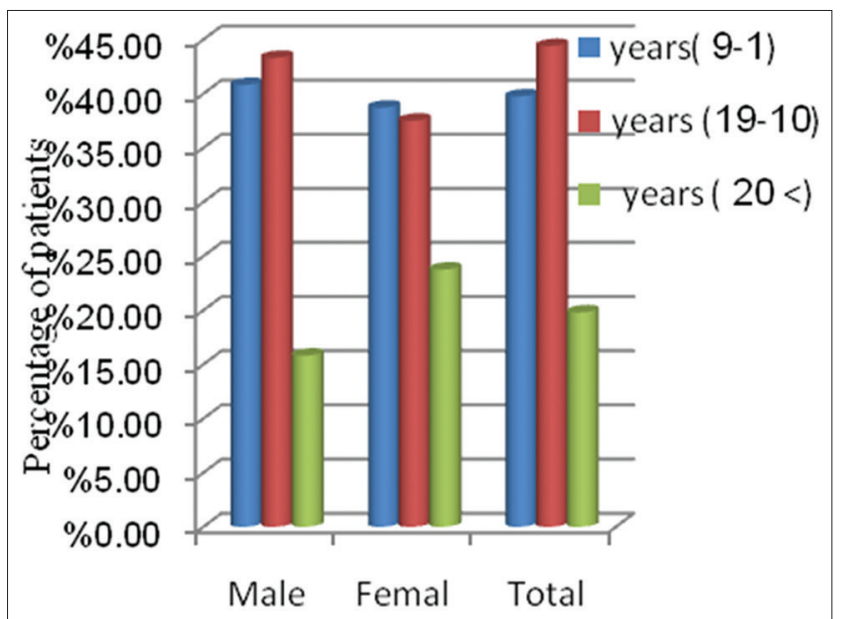

Fig. 2: The percentage of thalassemia patients by age categories and gender

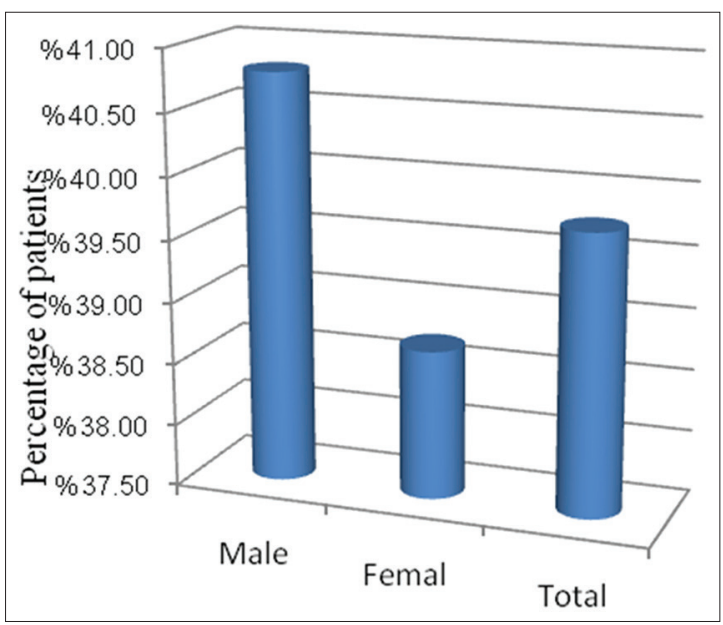

Fig. 3: The percentage of thalassemia patients by age

While in Table 1 , as for the association of thalassemia with blood groups, the results showed that the highest proportion of group is $0+$, where it represented $34 \%$, while the group $A B+$ was zero, while the groups $\mathrm{A}+, \mathrm{A}-, \mathrm{B}+, \mathrm{B}-, \mathrm{O}-$-, and $\mathrm{AB}+$ were $26.5 \%, 2.5 \%$, $25.5 \%, 1 \%, 3 \%$, and $7.5 \%$, respectively.

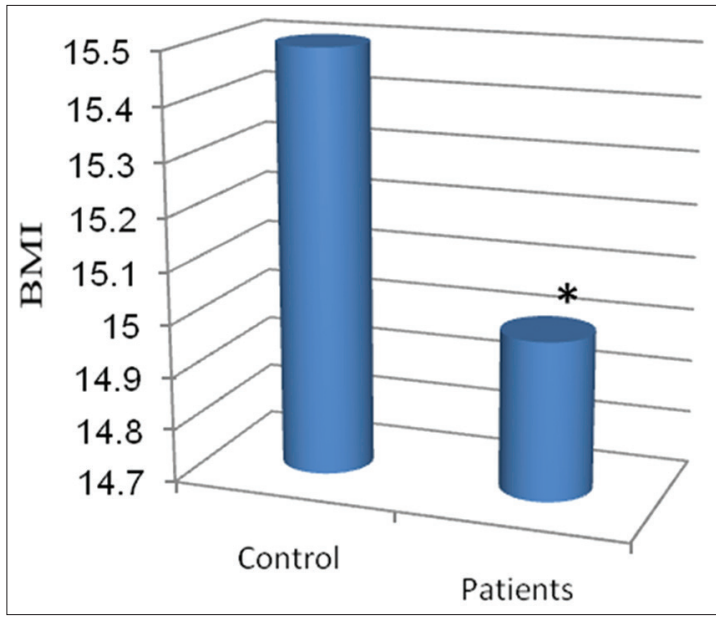

Fig. 4: Comparison between body mass index in patients with thalassemia and healthy people in the category (1-9) years

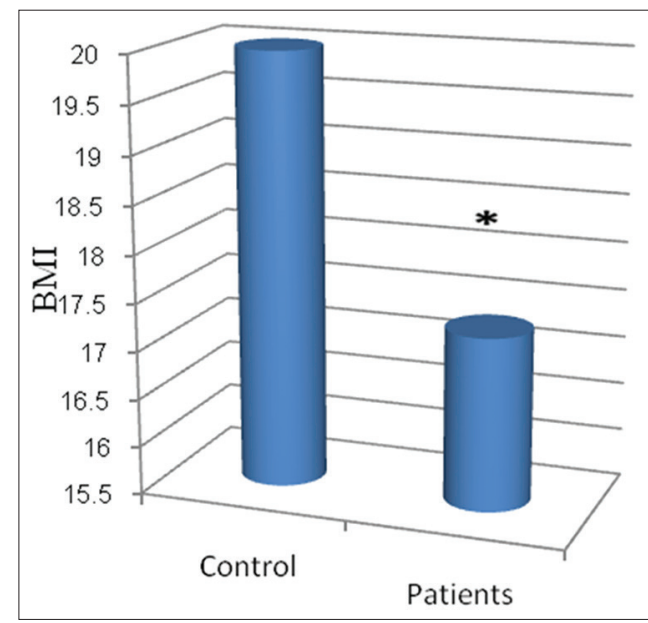

Fig. 5: Comparison of body mass index in patients with thalassemia and healthy people in the age group of 10-19 years

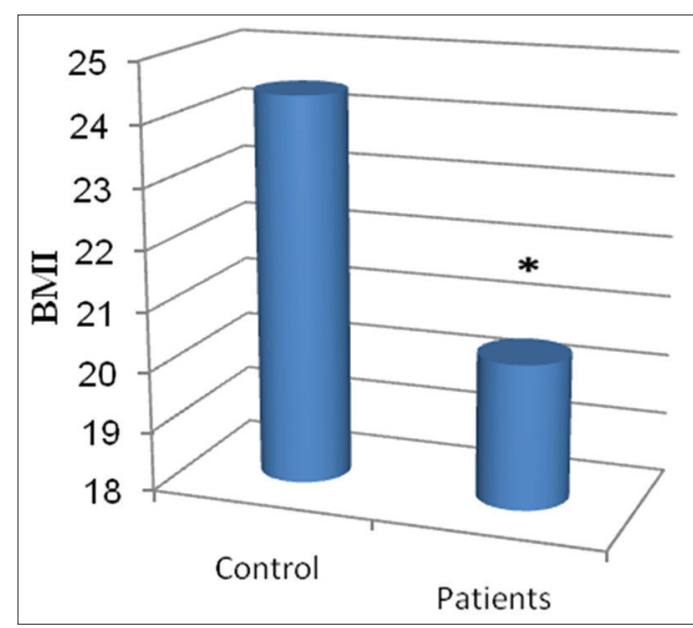

Fig. 6: Comparison of body mass index in patients with thalassemia and healthy individuals in the age group of $>20$ years

The results showed that thalassemia has a significant effect on the BMI where the results showed [Fig. 4] that the BMI for patients with thalassemia is less significant* $(\mathrm{p}<0.05)$ correlated with healthy in the category (1-9) years. 
Table 1: Percentage of blood groups of thalassemia and healthy patients

\begin{tabular}{lll}
\hline & \multicolumn{2}{l}{ Parameters } \\
\cline { 2 - 3 } & Thalassemia patient (\%) & Control (\%) \\
\hline Blood groups & & \\
$\mathrm{A}+$ & $53 / 200(26.5)$ & $8 / 60(13)$ \\
$\mathrm{A}-$ & $5 / 200(2.5)$ & $1 / 60(1)$ \\
$\mathrm{B}+$ & $51 / 200(25.5)$ & $13 / 60(21)$ \\
$\mathrm{B}-$ & $2 / 200(1)$ & $0 / 60(0)$ \\
$\mathrm{O}+$ & $68 / 200(34)$ & $33 / 60(55)$ \\
$\mathrm{O}-$ & $6 / 200(3)$ & $1 / 60(1)$ \\
$\mathrm{AB}+$ & $15 / 200(7.5)$ & $4 / 60(6)$ \\
$\mathrm{AB}-$ & & $0 / 60(0)$ \\
\hline
\end{tabular}

There was also a significant decrease* $(\mathrm{p}<0.05)$ in patients with thalassemia in the age group of 10-19 years compared to healthy in the same category in Fig. 5.

Thus, for the age group $>20$ years, the results showed that there is a significant decrease* $(\mathrm{p}<0.05)$ in the BMI in patients compared to healthy [Fig. 6].

\section{DISCUSSION}

The results of the current study showed that gender has a relationship with thalassemia, where the proportion of male infections is higher than that of females. Our study is consistent with a study of Baghianimoghadam et al. 2011, and this study found that the effect of thalassemia was more severe in males than in females, but differences were not significant. Another study found that the effect of sex was significant in patients with thalassemia. A study found that those with good health among thalassemia patients were $3.8 \%$ compared to healthy people who were 63\% [11]. The study of Biswas et al. in 2016 showed most patients to be within 15 years of age. Of 1711 patients, 1171 were under 10 , while 540 were between 11 and 30 years and none was found to be more than 30 years of age [12].

From Table 2, as for the association of thalassemia with blood groups, it can be concluded that the most common blood group observed in patients of thalassemia is $0+v e$ in $34 \%$ of the patients. With $26.5 \% \mathrm{~A}+\mathrm{ve}$ becomes the common blood group in the healthy people and $\mathrm{B}+\mathrm{ve} 25.5 \%$ while $\mathrm{AB}+, \mathrm{O}-$, $\mathrm{A}-$-, $\mathrm{B}-$ were $(7.5 \%, 3 \%$, $2.5 \%$ and $1 \%$ ) respectively. This study corresponds to Pranoti et al., in 2017, in which the most common blood group in ß-thalassemia patient is $\mathrm{O}+\mathrm{ve}$. Post- disease complication is commonly seen with $\mathrm{B}$ +ve. Early onset of beta-thalassemia is seen in A +ve and B +ve [7] while Mohammadali et al. reported $\mathrm{O}+\mathrm{ve}$ blood group to be common. In the research of association of $\mathrm{ABO}$ and $\mathrm{Rh}$ blood groups to blood-borne infections among blood donors in Tehran Iran [13]. Mohssin et al. studies of frequency, distribution of hemoglobin alternate, and $\mathrm{ABO}$ blood groups among thalassemia patients from Ibn-Al-Baladi, Hospital in Baghdad, Iraq, stated the similar fact of $\mathrm{O}$ blood group being common incidence (59.1\%) and $\mathrm{AB}$ with the least common event of the disease ß-thalassemia [14], whereas Saha et al. found in their study of frequency and distribution of blood groups in the donors of a rural hospitals, West Bengal, also got the finding of blood Group B being common in blood donors [15]. Iqbal et al., seen frequency of $\mathrm{ABO}$ and Rh blood groups in healthy donors, had reported the same finding that B blood group is common among the donors [16]. BMI is one of the methods to assess underweight, healthy, overweight, and obese children/patients As both underweight and obesity are associated with many health problems including coronary risks, it is very vital to detect these derangements as early as possible to prevent the consequent impending hazards. There are several studies which show that majority of beta thalassemia patients are underweight. One study showed that around two-thirds $(60 \%)$ of thalassemics are underweight and the rest were healthy and overweight [17]. The BMI for patients with thalassemia was significantly decreased $(p<0.05)$ to patient compared to healthy and all age groups.
In Muhammad et al. study, the age range of the patients of thalassemia major was 2-16 years mean BMI was total 179 (58.69\%) patients were underweight, 109 (35.74\%) patients were healthy, 10 (3.28\%) patients were overweight, and 7 (2.3\%) patients were obese [18]. Perhaps, it may be the reason the toxic effects of deferrioxamine, causing excess deposition in tissues and impairing iron dependent enzymes which modify the collagens, are thought to be the causes of growth defects. Similarly, low hemoglobin, high ferritin levels, and below normal iron chelation are thought to be additional factors $[19,20]$. Almost similar findings were shown by another study that thalassemia major patients had lower rate of growth and lower BMI which was attributed to low hemoglobin, high ferritin levels, and suboptimal iron chelation [20]. Kumari et al. carried out a study in

India which showed that $68.9 \%$ of thalassemic children were underweight, i. e., malnourished [21]. Furthermore, the study of Elabd et al. in 2017 appeared that subjects had the difference between patients and controls in height, weight with $\mathrm{p}=0.001$, and BMI with $\mathrm{p}=0.033$ [22].

\section{CONCLUSION}

Our study fining the results of the current study showed that gender has a relationship with thalassemia, where the proportion of male infection is higher than that of females. As for the association of thalassemia with blood groups, it can be concluded that the most common blood group observed in patients of thalassemia is $\mathrm{O}+\mathrm{ve}$, while the BMI for patients with thalassemia was significantly decreased $(p<0.05)$ to patient compared to healthy and all age groups.

\section{REFERENCES}

1. Al-Mosawy WF. The beta-thalassemia. Sci J Med Res 2017;1:24-30 .

2. What Are Thalassemia? NHLBI. Available from: [Last accessed on 2012 Jul 03; Last retrieved on 2016 Sep 05].

3. What Causes Thalassemia's? NHLBI. Available from: [Last accessed on 2012 Jul 03; Last retrieved on 2016 Sep 05].

4. Victor, et al. 1999. Introduction-1.1- Thallassemia-1.1.3. Classification

5. Pearson HA, Cohen AR, Giardina PJ, Kazazian HH. The changing profile of homozygous beta-thalassemia: Demography, ethnicity, and age distribution of current North American patients and changes in two decades. Pediatrics 1996;97:352-6.

6. Dinsdale H, Ridler C, Ells L. A simple guide to classifying body mass index in children. Oxford: National Obesity Observatory; 2011.

7. Sinha PA, Mulkutkar S, Bhavani JB. Study of distribution of ABO blood groups in ß-thalassemia patients. Int J Res Med Sci 2017;5:3479-83.

8. Garrow JS, Webster J. Quetelts index (W/H2) as measure of afatness. Int J Obesit 1985;9:147-53

9. Tippett P. Sub-division of the Rh(D) antigen. Med Lab Sci 1988;45:88-93.

10. Messeter L, Brodin T, Chester MA, Löw B, Lundblad A. Mouse monoclonal antibodies with Anti - A, Anti B and Anti A,B specificities, some superior to human polyclonal ABO reagents. Vox Sang 1984:46:185-94

11. Baghianimoghadam M, Sharifira G, Rahaei Z, Baghianimoghadam B, Heshmati $\mathrm{H}$. Health related quality of life in children with thalassemia assessed on the basis of SF -20 questionnaire in yazd, Iran: Ascaecontrol study centere. Eur J Public Health 2011;19:165-9.

12. Biswas A, Sarkar K, Firaus R, Saha K, Gupta D, Ghosh M, et al. Prevalence of anti-HCV, HBSAG, Hiv among multi-transfused thalassemic individuals and their socio-economic background in eastern india. Asian J Pharm Clin Res 2016;9:314-8.

13. Mohammadali F, Pourfathollah A. Association of ABO and Rh blood groups to blood borne infections among blood donors in Tehran-Iran. Iranian J Public Health 2014;43:981-9.

14. Mohssin MY, Mahmood AE, Kamal SB, Batah EH. Frequency distribution of hemoglobin variant and $\mathrm{ABO}$ blood groups among thalassemia patients fromIbn-Al-Baladi pediatric hospital in Baghdad/ Iraq. World J Pharm Pharm Sci 2015;4:31-9.

15. Saha AK, Sahadalal BS. Frequency and distribution of blood groups in the donors of a rural hospitals, West Bengal, India. Int J Pharm Biol Sci 2016; 7:B414-8.

16. Iqbal M, Niazi A, Tahir M. Frequency of ABO and Rh blood groups in healthy donors. J Rawalpindi Med Coll 2009;13:92-4.

17. Salih KM, Al-Mosawy WF. Evaluation some consequences of thalassemia major in splenectomized and non-splenectomized Iraqi patients. Int J Pharm Pharm Sci 2013;5:385-8. 
18. Muhammad AS, Muhammad US, Muhammad S. The assessment of nutritional status of children with beta thalassemia major with body mass index. Pharm J Med Health Sci 2017;11:262-5.

19. Olivieri NF, Koren G, Harris J, Khattak S, Freedman MH, Templeton DM, et al. Growth failure and bony changes induced bydeferoxamine. Am J Pediatr Hematol Oncol 1992;14:48-56.

20. Saxena A. Growth retardation in thalassemia major patients. Int J Hum Genet 2003;3:237-46.
21. Kumari V, Upadhyay SK, Gupta V, Piplani KS, Bhatia BD. Growth retardation and malnutrition in children with thalassemia major. Indian J Prevent Soc Med 2012;43:149-52.

22. Elabd M, Abu Zeid D, Elhady MA, El-Wakeel MA, El-Kassas GM, Sabry RN, et al. Increased urinary 8-oxo-7,8-dihydro-2'-deoxyguanosine excretion in a sample of egyptian children with beta thalassemia major: Marker for lipid peroxidation-induced dna damage. Asian J Pharm Clin Res 2017;10:171-4. 